\title{
TEMPERATURE BEHAVIOUR OF OPTICAL ABSORPTION EDGE AND PHASE TRANSITIONS IN $\mathrm{Cu}_{6} \mathrm{PS}_{5} \mathrm{I}_{0.8} \mathrm{Cl}_{0.2}$ SUPERIONIC MIXED CRYSTALS
}

\author{
I.P. Studenyak ${ }^{\text {a }}$, V.Yu. Izai ${ }^{\text {a }}$, V.V. Panko ${ }^{\text {b }}$, A.F. Orliukas ${ }^{\text {b }}$, E. Kazakevičius ${ }^{\text {b }}$, \\ F. Koleli ${ }^{\mathrm{c}}$, M. Dudukcu ${ }^{\mathrm{c}}$, and R. Aydin ${ }^{\mathrm{c}}$ \\ ${ }^{a}$ Uzhhorod National University, 46 Pidhirna St, 88000 Uzhhorod, Ukraine \\ E-mail: studenyak@dr.com \\ ${ }^{\mathrm{b}}$ Faculty of Physics, Vilnius University, Sauletekio 9, LT-10222 Vilnius, Lithuania \\ ${ }^{\mathrm{c}}$ Mersin University, Ciftlik-koy, 33342 Mersin, Turkey
}

Received 28 January 2009; revised 16 March 2009; accepted 19 March 2009

\begin{abstract}
Isoabsorption and spectral temperature studies of absorption edge of $\mathrm{Cu}_{6} \mathrm{PS}_{5} \mathrm{I}_{0.8} \mathrm{Cl}_{0.2}$ superionic mixed crystals are performed. Phase transition temperatures are determined and the transitions are identified. The optical absorption edge shape is studied in the temperature range $77-320 \mathrm{~K}$, the parameters of electron-phonon interaction, resulting in the Urbach behaviour of the optical absorption edge, are determined, temperature dependences of the optical pseudogap and Urbach energy are obtained.
\end{abstract}

Keywords: superionic mixed crystals, optical absorption edge, Urbach rule, phase transitions

PACS: $78.40 . \mathrm{Ha}, 77.80 . \mathrm{Bh}$

\section{Introduction}

$\mathrm{Cu}_{6} \mathrm{PS}_{5} \mathrm{X}(\mathrm{X}=\mathrm{I}, \mathrm{Cl})$ superionic conductors belong to the compound with argyrodite crystal structure and are characterized by high values of electrical conductivity and low values of activation energy [1-3]. At low temperatures these crystals undergo two phase transitions, one of them being a first-order superionic phase transition which is realised at $T_{\mathrm{I}}=170 \mathrm{~K}$ for $\mathrm{Cu}_{6} \mathrm{PS}_{5} \mathrm{I}$ and $T_{\mathrm{I}}=165 \mathrm{~K}$ for $\mathrm{Cu}_{6} \mathrm{PS}_{5} \mathrm{Cl}$, and the other is a secondorder structural phase transition which is realised at $T_{\mathrm{II}}=269 \mathrm{~K}$ for $\mathrm{Cu}_{6} \mathrm{PS}_{5} \mathrm{I}$ and $T_{\mathrm{II}}=241 \mathrm{~K}$ for $\mathrm{Cu}_{6} \mathrm{PS}_{5} \mathrm{Cl}$ $[4,5]$. At room temperature $\left(T>T_{\mathrm{II}}\right) \mathrm{Cu}_{6} \mathrm{PS}_{5} \mathrm{X}$ crystals belong to the cubic syngony ( $F \overline{4} 3 \mathrm{~m}$ space group) [1]. According to Ref. [6], at $T_{\mathrm{I}}<T<T_{\mathrm{II}} \mathrm{Cu}_{6} \mathrm{PS}_{5} \mathrm{I}$ crystals belong to a cubic superstructure $(F \overline{4} 3 c$ space group), while at $T<T_{\mathrm{I}}$ to the monoclinic syngony ( $C c$ space group).

Thermodynamical, dielectric, acoustic, and optical properties of $\mathrm{Cu}_{6} \mathrm{PS}_{5} \mathrm{X}$ crystals were studied in Refs. [4, 5,7-12]. It should be noted that the earlier studies of $\mathrm{Cu}_{6} \mathrm{PS}_{5} \mathrm{I}$ crystal absorption edge at high absorption levels have shown the existence of bound and free excitons at temperatures below the superionic phase transition, which undergo considerable changes with the temperature increase [11]. At the transition to the superionic state not only the exciton structure is changed, but also exponential parts at the longwave absorption edge appear. Contrary to $\mathrm{Cu}_{6} \mathrm{PS}_{5} \mathrm{I}$, in $\mathrm{Cu}_{6} \mathrm{PS}_{5} \mathrm{Cl}$ crystal [12] no excitonic bands are observed near the absorption edge at low temperatures. At $T>T_{\mathrm{I}}$ for $\mathrm{Cu}_{6} \mathrm{PS}_{5} \mathrm{X}$ crystals the temperature behaviour of exponential parts of the absorption edge is described by the empirical Urbach rule [13]:

$$
\begin{gathered}
\alpha(h \nu, T)=\alpha_{0} \exp \left[\frac{\sigma\left(h \nu-E_{0}\right)}{k T}\right]= \\
\alpha_{0} \exp \left[\frac{h \nu-E_{0}}{E_{\mathrm{U}}(T)}\right],
\end{gathered}
$$

where $E_{\mathrm{U}}$ is the Urbach energy (a reciprocal of the absorption edge slope $\left.E_{\mathrm{U}}^{-1}=\Delta(\ln \alpha) / \Delta(h \nu)\right), \sigma$ is the absorption edge steepness parameter, $\alpha_{0}$ and $E_{0}$ are the convergence point coordinates of the Urbach bundle.

The present work is aimed at the crystal growth, isoabsorption, and spectral studies of optical absorption edge as well as influence of $\mathrm{I} \rightarrow \mathrm{Cl}$ anionic substitution and related compositional disordering of the crystal lattice on the phase transitions and optical absorption edge parameters in $\mathrm{Cu}_{6} \mathrm{PS}_{5} \mathrm{I}_{0.8} \mathrm{Cl}_{0.2}$ superionic mixed crystals. 


\section{Experiment}

$\mathrm{Cu}_{6} \mathrm{PS}_{5} \mathrm{I}_{0.8} \mathrm{Cl}_{0.2}$ mixed crystals were grown using chemical vapour transport method. The synthesis from extra pure $\mathrm{Cu}, \mathrm{P}, \mathrm{S}$, and $\mathrm{CuX}(\mathrm{X}=\mathrm{I}, \mathrm{Cl})$ compounds, additionally purified by distillation in vacuum, was performed. 10-20 mg of $\mathrm{CuI}$ and $\mathrm{CuCl}$ in corresponding proportion per $1 \mathrm{~cm}^{3}$ of the ampoule free volume were used as a transport agent. The temperature at the hot end of the vessel was kept at 923 to $973 \mathrm{~K}$, and at the cool one at 873 to $923 \mathrm{~K}$. Thus grown crystals had the shape of plane-parallel plates $\left(5 \times 5 \times 2 \mathrm{~mm}^{3}\right)$ or distorted tetrahedrons $\left(4 \times 4 \times 4 \mathrm{~mm}^{3}\right)$.

The isoabsorption temperature studies consisted in measuring the absorption edge energy position $E_{g}^{\alpha}$ at the fixed value of absorption coefficient $\alpha$. Spectral dependence of the absorption coefficient $\alpha$ was studied in the temperature range 77-320 K using the set-up described in Ref. [14]. A MDR-3 diffraction monochromator was used for transmittance and reflectance measurements. The spectral slit was about $1 \AA$ A. A UTREX cryostat was applied, the temperature being stabilized within $0.1 \mathrm{~K}$. The linear absorption coefficient $\alpha$ as a function of transmittance $T r$ and reflection of the surface $R$ were calculated using the well-known formula, which takes into account multiple internal reflections [14]:

$$
\alpha=\frac{1}{d}\left\{\frac{(1-R)^{2}}{2 T r}+\sqrt{\left[\frac{(1-R)^{2}}{2 T r}\right]^{2}+R^{2}}\right\},
$$

where $d$ denotes the plane-parallel sample thickness. The sample thicknesses in our measurements varied from 50 to $100 \mu \mathrm{m}$, the relative error in the absorbance measurements $\Delta \alpha / \alpha$ not exceeding $10 \%$ at $0.3 \leq \alpha d \leq$ 3 [15].

\section{Results and discussion}

The isoabsorption studies showed that within the temperature interval $77-130 \mathrm{~K}$ the spectral position of absorption edge $E_{g}^{\alpha}$ remains unchanged, at $T>130 \mathrm{~K}$ the absorption edge shifts to the long-wavelength side, at $T_{\mathrm{I}}=(184 \pm 1) \mathrm{K}$ (determined at heating) the anomalous stepwise behaviour of the $E_{g}^{\alpha}$ with $\mathrm{d} E_{g}^{\alpha} / \mathrm{d} T>0$ is observed (Fig. 1). The stepwise behaviour of $E_{g}^{\alpha}$ and temperature hysteresis $\Delta T=6 \mathrm{~K}$ describe the phase transition at $T=T_{\mathrm{I}}$ as the first-order phase transition. The long-wavelength shift of absorption edge is observed at $T>T_{\mathrm{I}}$ and typical change of the slope of the $E_{g}^{\alpha}(T)$ plot is realized in the temperature interval of the second-order phase transition $T_{\mathrm{II}}=(240-260) \mathrm{K}$.

Absorption edge studies in $\mathrm{Cu}_{6} \mathrm{PS}_{5} \mathrm{I}_{0.8} \mathrm{Cl}_{0.2}$ crystals have shown that in the temperature interval un-

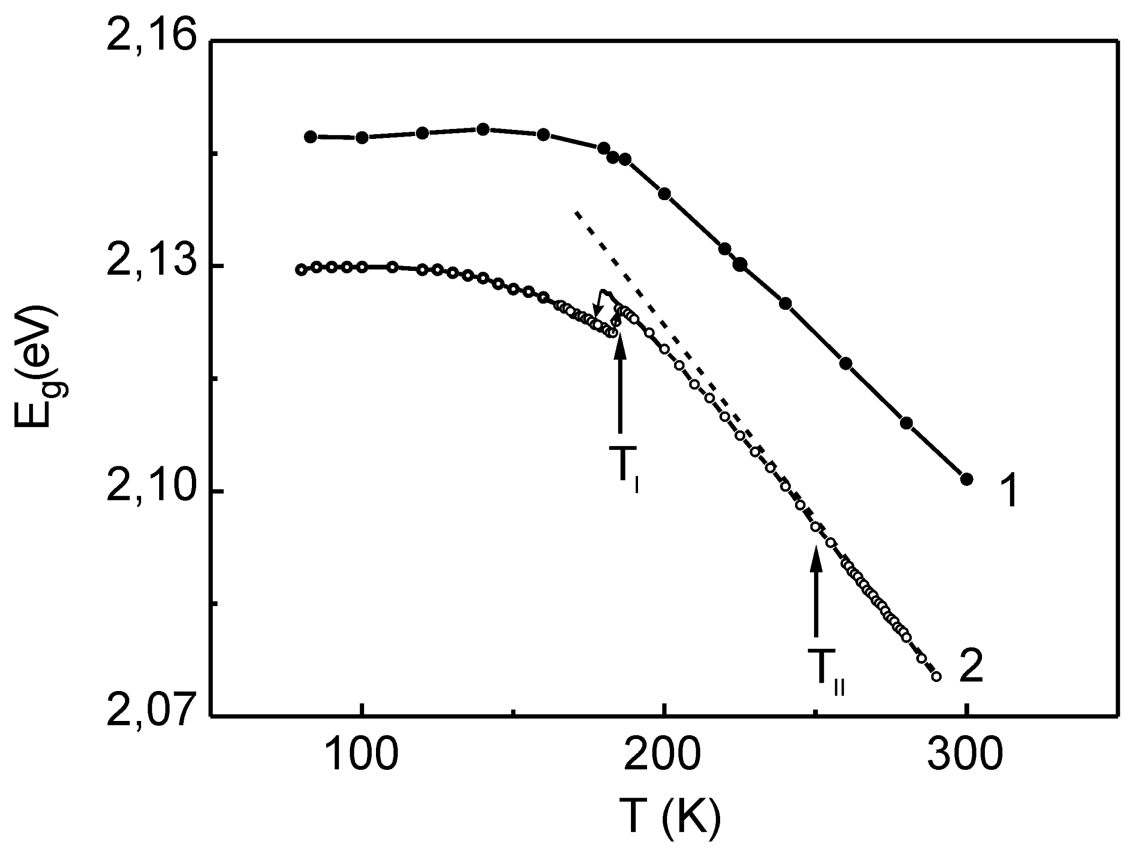

Fig. 1. Temperature dependences of the optical pseudogap $E_{g}^{*}(1)$ and absorption edge energy position $E_{g}^{\alpha}$ at $\alpha=250 \mathrm{~cm}^{-1}(2)$ at cooling and heating in $\mathrm{Cu}_{6} \mathrm{PS}_{5} \mathrm{Cl}_{0.2} \mathrm{I}_{0.8}$ mixed crystals. The solid lines are drawn to guide the eye, the dashed line is obtained by fitting the data for $T>T_{\text {II }}$ to the Eq. (4). 
der investigation the absorption edge has exponential shape, at $T>T_{\mathrm{I}}$ the temperature behaviour of absorption edge is described by the Urbach rule, the coordinates of the Urbach absorption edge convergency point remain unchanged at $T=T_{\mathrm{II}}$ and have the values $\alpha_{0}=4.04 \cdot 10^{5} \mathrm{~cm}^{-1}$ and $E_{0}=2.229 \mathrm{eV}$ (Figs. 2, $3)$. From the temperature dependence of the absorp- tion edge steepness parameter $\sigma$, the parameters of electron-phonon interaction (EPI) are obtained according to [16]:

$$
\sigma(T)=\sigma_{0} \frac{2 k T}{\hbar \omega_{\mathrm{p}}} \cdot \tanh \left(\frac{\hbar \omega_{\mathrm{p}}}{2 k T}\right)
$$

where $\hbar \omega_{\mathrm{p}}$ is the effective phonon energy in a singleoscillator model, describing the EPI, and $\sigma_{0}$ is a param-

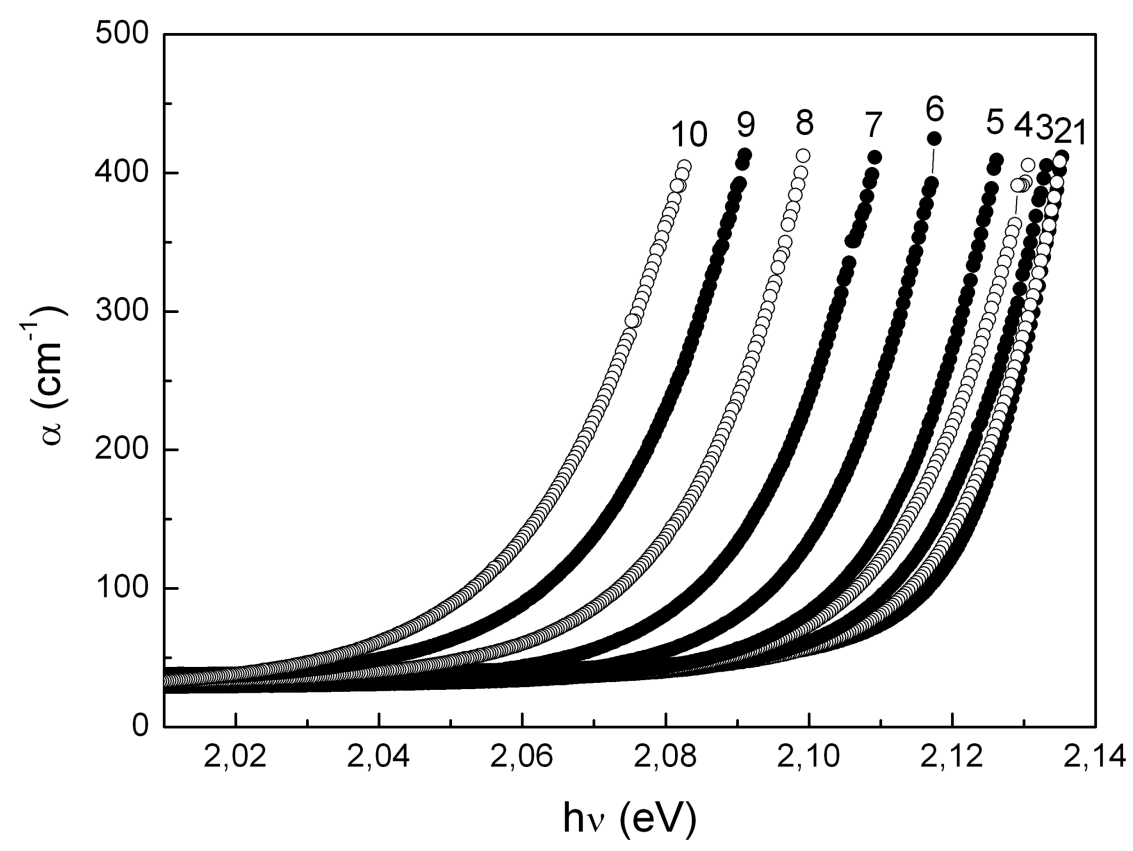

Fig. 2. Spectral dependences of $\mathrm{Cu}_{6} \mathrm{PS}_{5} \mathrm{Cl}_{0.2} \mathrm{I}_{0.8}$ mixed crystal absorption coefficient at various temperatures: 1 at $83 \mathrm{~K}, 2$ at $140 \mathrm{~K}, 3$ at $160 \mathrm{~K}, 4$ at $180 \mathrm{~K}, 5$ at $200 \mathrm{~K}, 6$ at $220 \mathrm{~K}, 7$ at $240 \mathrm{~K}, 8$ at $260 \mathrm{~K}, 9$ at $280 \mathrm{~K}, 10$ at $300 \mathrm{~K}$.

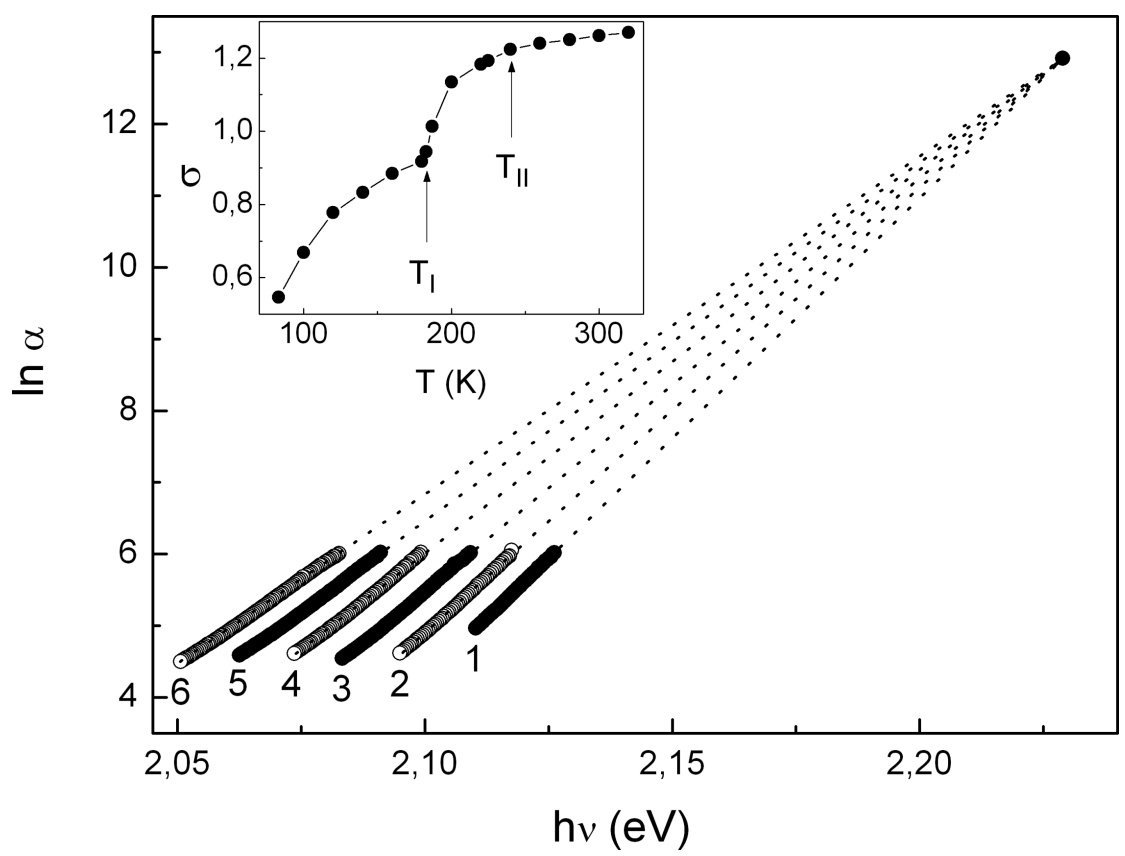

Fig. 3. Spectral dependences of the Urbach absorption edge for $\mathrm{Cu}_{6} \mathrm{PS}_{5} \mathrm{Cl}_{0.2} \mathrm{I}_{0.8}$ mixed crystals at various temperatures: 1 at $200 \mathrm{~K}, 2$ at $220 \mathrm{~K}, 3$ at $240 \mathrm{~K}, 4$ at $260 \mathrm{~K}, 5$ at $280 \mathrm{~K}, 6$ at $300 \mathrm{~K}$. The inset shows the temperature dependence of steepness parameter $\sigma$. 
Table 1. Convergence point coordinates $\alpha_{0}$ and $E_{0}$ of the Urbach absorption edge, parameters of EPI $\hbar \omega_{\mathrm{p}}$ and $\sigma_{0}$, Einstein temperature $\Theta_{\mathrm{E}}$, phase transition temperatures $T_{\mathrm{I}}$ and $T_{\mathrm{II}}$, parameters $E_{g}^{*}(0), S_{g}^{*},\left(E_{\mathrm{U}}\right)_{0}$, and $\left(E_{\mathrm{U}}\right)_{1}$ for $\mathrm{Cu}_{6} \mathrm{PS}_{5} \mathrm{I}$ and $\mathrm{Cu}_{6} \mathrm{PS}_{5} \mathrm{Cl}$ single crystals as well as for $\mathrm{Cu}_{6} \mathrm{PS}_{5} \mathrm{I}_{0.8} \mathrm{Cl}_{0.2}$ mixed crystals.

\begin{tabular}{|c|c|c|c|c|c|c|}
\hline \multirow{2}{*}{$\begin{array}{l}\text { Crystal } \\
\text { Temperature region }\end{array}$} & \multicolumn{2}{|c|}{$\mathrm{Cu}_{6} \mathrm{PS}_{5} \mathrm{I}$} & \multicolumn{2}{|c|}{$\mathrm{Cu}_{6} \mathrm{PS}_{5} \mathrm{Cl}_{0.2} \mathrm{I}_{0.8}$} & \multicolumn{2}{|c|}{$\mathrm{Cu}_{6} \mathrm{PS}_{5} \mathrm{Cl}$} \\
\hline & $T>T_{\mathrm{II}}$ & $T<T_{\mathrm{II}}$ & $T>T_{\mathrm{II}}$ & $T<T_{\mathrm{II}}$ & $T>T_{\mathrm{II}}$ & $T<T_{\mathrm{II}}$ \\
\hline$\alpha_{0}, \mathrm{~cm}^{-1}$ & \multicolumn{2}{|c|}{$2.96 \cdot 10^{6}$} & \multicolumn{2}{|c|}{$4.04 \cdot 10^{5}$} & \multicolumn{2}{|c|}{$4.26 \cdot 10^{4}$} \\
\hline$E_{0}, \mathrm{eV}$ & \multicolumn{2}{|c|}{2.230} & \multicolumn{2}{|c|}{2.229} & \multicolumn{2}{|c|}{2.776} \\
\hline$\sigma_{0}$ & 1.55 & 1.52 & 1.34 & 1.51 & 0.27 & 0.28 \\
\hline$\hbar \omega_{\mathrm{p}}, \mathrm{meV}$ & 32 & 27 & 22 & 36 & 57 & 58 \\
\hline$\Theta_{E}, \mathrm{~K}$ & 371 & 313 & 252 & 416 & 662 & 673 \\
\hline$\left(E_{\mathrm{U}}\right)_{0}, \mathrm{meV}$ & 9.6 & 9.9 & 8.2 & 11.8 & 105.5 & 104.8 \\
\hline$\left(E_{\mathrm{U}}\right)_{1}, \mathrm{meV}$ & 23.2 & 15.8 & 16.2 & 23.8 & 191.8 & 200.0 \\
\hline$E_{g}^{*}(0), \mathrm{eV}$ & 2.152 & 2.157 & 2.173 & 2.170 & 2.384 & 2.392 \\
\hline$S_{g}^{*}$ & 5.6 & 5.4 & 6.1 & 5.9 & 12.0 & 14.5 \\
\hline$T_{\mathrm{I}}, \mathrm{K}$ & \multicolumn{2}{|c|}{170} & \multicolumn{2}{|c|}{184} & \multicolumn{2}{|c|}{165} \\
\hline$T_{\mathrm{II}}, \mathrm{K}$ & \multicolumn{2}{|c|}{269} & \multicolumn{2}{|c|}{$240-260$} & \multicolumn{2}{|c|}{241} \\
\hline
\end{tabular}

eter related to the EPI constant $g$ via $\sigma_{0}=(2 / 3) g^{-1}$. The values of the effective phonon energy $\hbar \omega_{\mathrm{p}}$ and the EPI parameter $\sigma_{0}$, obtained at the description of $\sigma(T)$ dependence (see the insets to Fig. 3), are listed in Table 1. For comparison the Urbach edge parameters and EPI parameters as well as the phase transition temperatures for $\mathrm{Cu}_{6} \mathrm{PS}_{5} \mathrm{I}$ and $\mathrm{Cu}_{6} \mathrm{PS}_{5} \mathrm{Cl}$ single crystals are also listed in Table 1. In $\mathrm{Cu}_{6} \mathrm{PS}_{5} \mathrm{I}_{0.8} \mathrm{Cl}_{0.2}$ mixed crystals $\sigma_{0}>1$, this being the evidence for weak EPI [17]. It should be noted that in the range of the phase transitions the features in the temperature dependence of $\sigma$ are observed (see the insets to Fig. 3) as well as the variation of $\hbar \omega_{\mathrm{p}}$ and $\sigma_{0}$ parameter values at $T=T_{\mathrm{II}}$ (Table 1 ).

Temperature dependences of the Urbach absorption edge parameters - optical pseudogap $E_{g}^{*}\left(E_{g}^{*}\right.$ is the absorption edge energy position at the fixed value of the absorption coefficient $\alpha=1000 \mathrm{~cm}^{-1}$ [12]) and Urbach energy $E_{\mathrm{U}}$ are shown in Fig. 4. The temperature dependences of $E_{g}^{*}$ and $E_{\mathrm{U}}$ for the temperature range where the Urbach shape of absorption edge is observed are well described in the framework of Einstein model by the relationships $[18,19]$

$$
\begin{aligned}
E_{g}^{*}(T) & =E_{g}^{*}(0)-S_{g}^{*} k \Theta_{\mathrm{E}}\left[\exp \left(\frac{\Theta_{\mathrm{E}}}{T}\right)-1\right]^{-1}, \\
E_{\mathrm{U}} & =\left(E_{\mathrm{U}}\right)_{0}+\left(E_{\mathrm{U}}\right)_{1}\left[\exp \left(\frac{\Theta_{\mathrm{E}}}{T}\right)-1\right]^{-1},
\end{aligned}
$$

where $S_{g}^{*}$ is a dimensionless constant of interaction, $\Theta_{\mathrm{E}}$ is the Einstein temperature corresponding to the average frequency of phonon excitations of a system of noninteracting oscillators, $\left(E_{\mathrm{U}}\right)_{0}$ and $\left(E_{\mathrm{U}}\right)_{1}$ are constant values. The Einstein temperature is related to the Debye temperature $\Theta_{\mathrm{D}}$ as $\Theta_{\mathrm{E}} \approx(3 / 4) \Theta_{\mathrm{D}}$ [20]. The ad- justment parameters $E_{g}^{*}(0), S_{g}^{*}, \Theta_{\mathrm{E}},\left(E_{\mathrm{U}}\right)_{0}$, and $\left(E_{\mathrm{U}}\right)_{1}$ are listed in Table 1. The most noticeable anomaly in the range of the phase transitions is observed at $T=T_{\mathrm{I}}$ in the temperature dependence of $E_{\mathrm{U}}$ (Fig. 4). Other features are revealed weakly that can be related to the $\mathrm{Cu}_{6} \mathrm{PS}_{5} \mathrm{I}_{0.8} \mathrm{Cl}_{0.2}$ mixed crystal lattice disordering.

The Urbach energy is known to characterize the degree of edge smearing due to the crystal lattice disordering caused by specific features of its structure as well as induced by external factors [21]. Besides the temperature-related disordering due to thermal vibrations of the lattice, superionic crystals are characterized by structural disordering. In superionic conductors the structural disordering is caused by non-equivalence between the number of mobile ions and positions which they can occupy, and is related only to the sublattice of the mobile ions since the rigid sublattice preserves its regular structure. In Ref. [12] it was shown for $\mathrm{Cu}_{6} \mathrm{PS}_{5} \mathrm{X}$ crystals that in fast-ion conductors the structural disordering in superionic phase consists of two components - dynamical and static. Static structural disordering in $\mathrm{Cu}_{6} \mathrm{PS}_{5} \mathrm{X}$ crystals, due to the structure deficiency, results in local non-uniform electric fields which, in turn, result in additional smearing of the band edges. Dynamical structural disordering in the superionic phase arises due to the hopping motion of copper ions participating in ion transport and providing high ionic conductivity.

In $\mathrm{Cu}_{6} \mathrm{PS}_{5} \mathrm{I}_{0.8} \mathrm{Cl}_{0.2}$ mixed crystals, besides the temperature-related (due to the lattice thermal vibrations) and structural (static and dynamical) disordering typical of pure $\mathrm{Cu}_{6} \mathrm{PS}_{5} \mathrm{X}$ crystals, compositional disordering should also be revealed. According to Ref. [22], the 


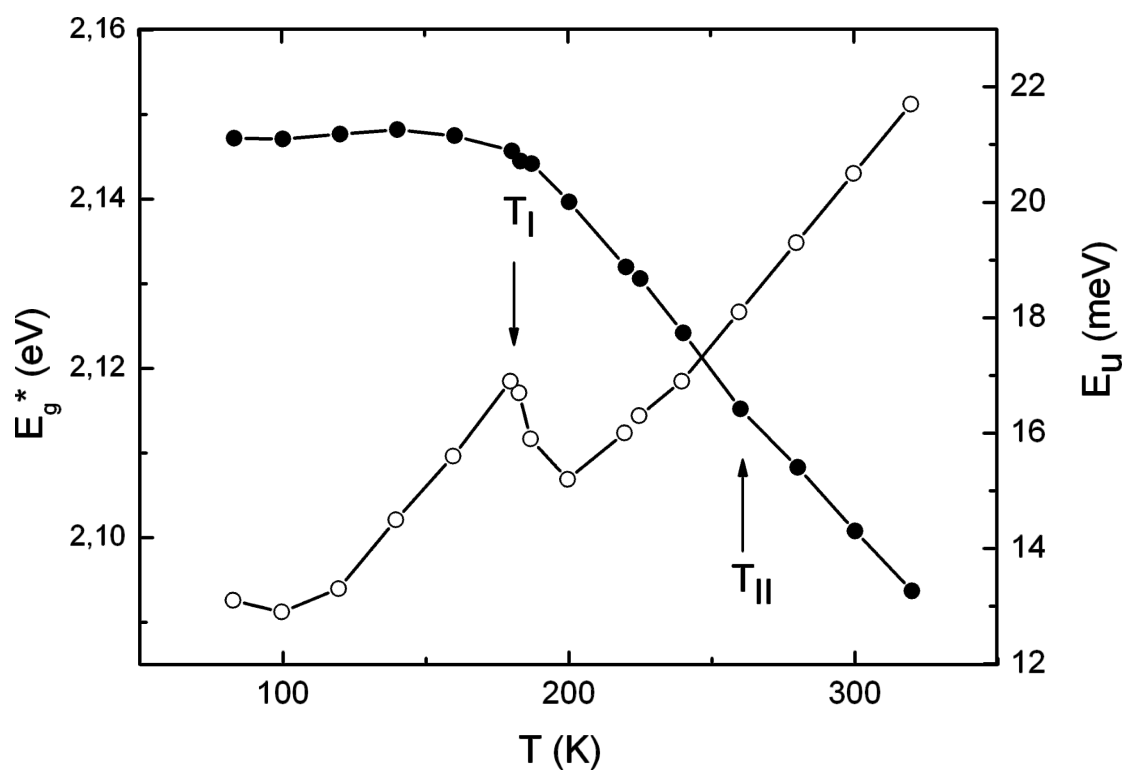

Fig. 4. Temperature dependences of the optical pseudogap $E_{g}^{*}(1)$ and Urbach energy $E_{\mathrm{U}}(2)$ for $\mathrm{Cu}_{6} \mathrm{PS}_{5} \mathrm{Cl}_{0.2} \mathrm{I}_{0.8}$ mixed crystals. The lines are drawn to guide the eye.

effect of different types of disordering on the Urbach energy in mixed crystals is given by

$E_{\mathrm{U}}=\left(E_{\mathrm{U}}\right)_{\mathrm{X}}+\left(E_{\mathrm{U}}\right)_{T}+\left(E_{\mathrm{U}}\right)_{\mathrm{C}}=\left(E_{\mathrm{U}}\right)_{\mathrm{X}, \mathrm{C}}+\left(E_{\mathrm{U}}\right)_{T}$,

where $\left(E_{\mathrm{U}}\right)_{\mathrm{X}}$ and $\left(E_{\mathrm{U}}\right)_{\mathrm{C}}$ are the contributions of static structural and compositional disordering, respectively, and $\left(E_{\mathrm{U}}\right)_{T}$ reflects the effect of temperature-dependent types of disordering. It follows from the comparison of Eqs. (5) and (6) that $\left(E_{\mathrm{U}}\right)_{\mathrm{X}, \mathrm{C}} \equiv\left(E_{\mathrm{U}}\right)_{0}$ and $\left(E_{\mathrm{U}}\right)_{T} \equiv$ $\left(E_{\mathrm{U}}\right)_{1} /\left[\exp \left(\Theta_{\mathrm{E}} / T\right)-1\right]$. This enables one to estimate the contribution of various types of disordering into the Urbach energy $E_{\mathrm{U}}$. The performed calculations have shown that the contribution of $\left(E_{\mathrm{U}}\right)_{\mathrm{X}, \mathrm{C}}$ into $E_{\mathrm{U}}$ at $T=$ $300 \mathrm{~K}$ is $40 \%$ while that of $\left(E_{\mathrm{U}}\right)_{T}$ is $60 \%$. Thus, the absorption edge smearing at $T=300 \mathrm{~K}$ results mostly from the effect of temperature-dependent types of disordering, i. e. the effect of thermal vibrations of the lattice and dynamical structural disordering in the superionic phase due to the hopping motion of copper ions.

\section{Conclusions}

Absorption edge studies in $\mathrm{Cu}_{6} \mathrm{PS}_{5} \mathrm{I}_{0.8} \mathrm{Cl}_{0.2}$ mixed crystals have shown that in the temperature interval under investigation the absorption edge has exponential shape, at $T>T_{\mathrm{I}}$ the temperature behaviour of absorption edge is described by the Urbach rule, the coordinates of the Urbach absorption edge convergency point remain unchanged at $T=T_{\mathrm{II}}$. From the temperature dependence of the absorption edge steepness parameter $\sigma$, the parameters of electron-phonon interaction are obtained. The temperature dependences of Urbach absorption edge parameters such as optical pseudogap $E_{g}^{*}$ and Urbach energy $E_{\mathrm{U}}$ are well described in the framework of Einstein model. The analysis of Urbach absorption edge has shown a change of the character of the temperature dependences of $\sigma, E_{\mathrm{U}}$, and $E_{g}^{*}$ to be observed at the phase transitions.

\section{References}

[1] W.F. Kuhs, R. Nitsche, and K. Scheunemann, Vapour growth and lattice data of new compounds with icosahedral structure of the type $\mathrm{Cu}_{6} \mathrm{PS}_{5} \mathrm{Hal}(\mathrm{Hal}=\mathrm{Cl}, \mathrm{Br}$, I), Mater. Res. Bull. 11, 1115-1124 (1976).

[2] V.V. Panko, I.P. Studenyak, V.S. Dyordyai, Gy.S. Kovacs, A.N. Borets, and Yu.V. Voroshilov, Influence of preparation conditions on properties of $\mathrm{Cu}_{6} \mathrm{PS}_{5} \mathrm{Hal}$ crystals, Izv. Akad. Nauk SSSR, Neorg. Mater. [Inorg. Mater. (USSR)] 24, 120-123 (1988) [in Russian].

[3] R.B. Beeken, J.J. Garbe, and N.R. Petersen, Cation mobility in the $\mathrm{Cu}_{6} \mathrm{PS}_{5} \mathrm{X}(\mathrm{X}=\mathrm{Cl}, \mathrm{Br}, \mathrm{I})$ argyrodites, J. Phys. Chem. Solids 64, 1261-1264 (2003).

[4] I.P. Studenyak, R. Vaitkus, V.S. Dyordyai, A. Kezionis, V. Mikucionis, V.V. Panko, Gy.S. Kovacs, V.A. Stefanovich, A.F. Orliukas, A.N. Borets, and V.Yu. Slivka, Phase transitions in $\mathrm{Cu}_{6} \mathrm{PS}_{5} \mathrm{I}$ single crystals, Fiz. Tverd. Tela (Leningrad) [Sov. Phys. Solid State] 28, 25552557 (1986) [in Russian].

[5] I.P. Studenyak, V.O. Stefanovich, M. Kranjčec, D.I. Desnica, Yu.M. Azhniuk, Gy.Sh. Kovacs, and V.V. Panko, Raman scattering studies of $\mathrm{Cu}_{6} \mathrm{PS}_{5} \mathrm{Hal}$ $(\mathrm{Hal}=\mathrm{Cl}, \mathrm{Br}$, and I) fast-ion conductors, Solid State Ionics 95, 221-225 (1997). 
[6] A. Gagor, A. Pietraszko, and D. Kaynts, Diffusion paths formation for $\mathrm{Cu}^{+}$ions in superionic $\mathrm{Cu}_{6} \mathrm{PS}_{5} \mathrm{I}$ single crystals studied in terms of structural phase transition, J. Solid State Chem. 178, 3366-3375 (2005).

[7] S. Fiechter and E. Gmelin, Thermochemical data of argyrodite-type ionic conductors: $\mathrm{Cu}_{6} \mathrm{PS}_{5} \mathrm{Hal}$ ( $\mathrm{Hal}=$ Cl, Br, I), Thermochim. Acta 85, 155-158 (1985).

[8] I.P. Studenyak, Gy.S. Kovacs, A.F. Orliukas, and E.T. Kovacs, Temperature variations of dielectric and optical properties in phase transitions regions for $\mathrm{Cu}_{6} \mathrm{PS}(\mathrm{Se})_{5} \mathrm{Hal}$ superionic ferroelastics, Izv. Ross. Akad. Nauk, Ser. Fiz. [Bull. Russ. Acad. Sci., Phys. Ser.] 56, 86-93 (1992) [in Russian].

[9] V. Samulionis, V. Valevičius, I.P. Studeniak, and D.S. Kovač, Acoustic properties of superionic ferroelastic $\mathrm{Cu}_{6} \mathrm{PS}_{5} \mathrm{I}$ and $\mathrm{Cu}_{6} \mathrm{PS}_{5} \mathrm{Br}$ crystals, Ultragarsas (Ultrasonics) 25, 129-136 (1993).

[10] V. Samulionis, J. Banys, Y. Vysochanskii, and I. Studenyak, Investigation of ultrasonic and acoustoelectric properties of ferroelectric-semiconductor crystals, Ferroelectrics 336, 29-38 (2006).

[11] I.P. Studenyak, Gy.S. Kovacs, V.V. Panko, E.T. Kovacs, and A.N. Borets, Absorption edge and phase transitions in $\mathrm{Cu}_{6} \mathrm{PS}_{5} \mathrm{Hal}(\mathrm{Hal}=\mathrm{Br}, \mathrm{I})$ superionic crystals, Fiz. Tverd. Tela (Leningrad) [Sov. Phys. Solid State] 26, 2598-2602 (1984) [in Russian].

[12] I.P. Studenyak, M. Kranjčec, Gy.Sh. Kovacs, V.V. Panko, D.I. Desnica, A.G. Slivka, and P.P. Guranich, The effect of temperature and pressure on the optical absorption edge in $\mathrm{Cu}_{6} \mathrm{PS}_{5} \mathrm{X}(\mathrm{X}=\mathrm{Cl}, \mathrm{Br}, \mathrm{I})$ crystals, J. Phys. Chem. Solids 60, 1897-1904 (1999).

[13] F. Urbach, The long-wavelength edge of photographic sensitivity and electronic absorption of solids, Phys. Rev. 92, 1324-1326 (1953).

[14] I.P. Studenyak, M. Kranjčec, Gy.Sh. Kovacs, I.D. Desnica, V.V. Panko, and V.Yu. Slivka, Influence of compositional disorder on optical absorption processes in $\mathrm{Cu}_{6} \mathrm{P}\left(\mathrm{S}_{1-x} \mathrm{Se}_{x}\right)_{5} \mathrm{I}$ crystals, J. Mater. Res. 16, 1600-1608 (2001).

[15] F. Oswald, Zur Meßgenauigkeit bei der Bestimmung der Absorptionskonstanten von Halbleitern im infraroten Spektralbereich, Optik 16, 527-537 (1959).

[16] M.V. Kurik, Urbach rule, Phys. Status Solidi A 8, 9-45 (1971).

[17] H. Sumi and A. Sumi, The Urbach-Martiensen rule revisited, J. Phys. Soc. Jpn. 56, 2211-2220 (1987).

[18] M. Beaudoin, A.J.G. DeVries, S.R. Johnson, H. Laman, and T. Tiedje, Optical absorption edge of semi-insulating GaAs and InP at high temperatures, Appl. Phys. Lett. 70, 3540-3542 (1997).

[19] Z. Yang, K.P. Homewood, M.S. Finney, M.A. Harry, and K.J. Reeson, Optical absorption study of ion beam synthesized polycrystalline semiconducting $\mathrm{FeSi}_{2}$, J. Appl. Phys. 78, 1958-1963 (1995).

[20] G.D. Cody, T. Tiedje, B. Abeles, B. Brooks, and Y. Goldstein, Disorder and the optical-absorption edge of hydrogenated amorphus silicon, Phys. Rev. Lett. 47, 1480-1483 (1981).

[21] G.D. Cody, Urbach edge of crystalline and amorphous silicon: A personal review, J. Non-Cryst. Solids 141, 3-15 (1992).

[22] A. Skumanich, A. Frova, and N.M. Amer, Urbach tail and gap states in hydrogenated a-SiC and a-SiGe alloys, Solid State Commun. 54, 597-601 (1985).

\title{
OPTINIO SUGERTIES KRAŠTO TEMPERATŪRINIS ELGESYS IR FAZINIAI VIRSMAI $\mathrm{Cu}_{6} \mathrm{PS}_{5} \mathrm{I}_{0,8} \mathrm{Cl}_{0,2}$ SUPERJONINIAME LAIDININKE
}

\author{
I.P. Studenyak ${ }^{\text {a }}$, V.Yu. Izai ${ }^{\text {a }}$, V.V. Panko ${ }^{\text {a }}$, A.F. Orliukas ${ }^{\text {b }}$, E. Kazakevičius ${ }^{\text {b }}$, F. Koleli ${ }^{\text {c }}$, M. Dudukcu ${ }^{\text {c }}$, \\ R. Aydin ${ }^{\mathrm{c}}$ \\ ${ }^{\text {a } U z ̌ h o r o d o ~ n a c i o n a l i n i s ~ u n i v e r s i t e t a s, ~ U z ̌ h o r o d a s, ~ U k r a i n a ~}$ \\ ${ }^{\mathrm{b}}$ Vilniaus universiteto Fizikos fakultetas, Vilnius, Lietuva \\ ${ }^{\mathrm{c}}$ Mersino universitetas, Mersinas, Turkija
}

\section{Santrauka}

Atlikti maišyto $\mathrm{Cu}_{6} \mathrm{PS}_{5} \mathrm{I}_{0,8} \mathrm{Cl}_{0,2}$ kristalo izosugerties ir sugerties krašto spektriniai bei temperatūriniai tyrimai, identifikuoti faziniai virsmai ir įvertintos jų temperatūros. Optinès sugerties krašto forma buvo tiriama 77-300 K temperatūroje, nustatyti optinès sugerties krašto Urbacho elgesi lemiančios elektrono ir fonono sąveikos parametrai bei optinio pseudotarpo ir Urbacho energijos temperatūrinès priklausomybės. 